\title{
Resenha
}

\section{Vanguardas da Responsabilidade: Direito, Neurociências e Inteligência Artificial}

Review

Vanguards of Responsibility: Law, Neurosciences and Artificial Intelligence

Reseña

Vanguardias de Responsabilidad: Derecho, Neurociencias e Inteligencia Artificial

José Pedro Matos Fernandes ${ }^{1}$

Esse é um livro não só multidimensional, porque aborda um assunto sob diversos prismas, olhando para diversas faces de um mesmo objeto, como é também uma obra multihermenêutica, por conter diferentes interpretações de mesmo conceito, ou melhor, de uma mesma ideia. Nele, trata-se de perceber a responsabilidade em campos tão diferentes como as neurociências, a bioética, o direito, o desenvolvimento de biotecnologias, das ciências da computação e inteligência artificial e da filosofia, ao mesmo tempo que nos dá diversas perspetivas sobre uma ideia que, na aparência, é tão simples e desejável. Nada pode parecer tão óbvio como o cenário em que deveríamos ser todos responsáveis, em que o nível de responsabilidade cresce à medida das exigências do desenvolvimento científico e tecnológico. Sobretudo quando novos instrumentos nos possibilitam aceder a locais onde supostamente se produz a responsabilidade - o cérebro - e quando os contextos civilizacionais nos colocam em terrenos que não dominamos totalmente (nem tão pouco sabemos o que poderá significar essa totalidade), mas que todos pressentimos que estamos a lidar com uma realidade espantosamente gigantesca, movediça e, até perigosa.

O título da obra incorpora de imediato essa posição relativa ao problema: é uma abordagem de vanguarda. Ora, a vanguarda pretende desbravar caminhos (criar veredas no meio do ambiente selvagem), ser de algum modo pioneiro, e portanto, arriscar explorar territórios, avançar por realidades recentemente criadas e, por certo, desafiar certezas e convicções que muitas vezes utilizamos nos nossos argumentos e nas nossas práticas quando nos referimos a esta ideia.

\footnotetext{
1 Doutor; professor coordenador do Instituto Politécnico de Beja, Portugal; diretor da Escola Superior de Educação, Beja, Portugal. E-mail: fernandes.josepedro@gmail.com
} 
O assunto é um dos mais espinhosos, em termos filosóficos. Um dos grandes reptos, que é lançado logo no prefácio, da autoria de Manuel Curado, problematizando a própria ideia de responsabilidade, reflecte a consciência de que a utilizamos "sem se saber muito bem o que é" (2, p. 7). É claro que esta ignorância não resulta da sua novidade, ou da negligência na sua teorização. O problema é mais radical. Resulta da sua extensão, da sua contaminação com pressuposto ideológicos e se situar num horizonte misto, de confluência entre pessoal e o social, entre o que é e o que deve ser, entre o emocional e o racional, entre o voluntário e o involuntário, entre a ideia de liberdade e o da necessidade. Por tudo isto, é um assunto difícil. Para além disso, tem consequências tremendas, pois afeta a esfera do legítimo, do imputável, do bem e do mal, do que se passa na alma de cada um de nós e da naturalidade ou artificialidade da sua existência. A questão pode mesmo chegar a colocarse no patamar escorregadio de um limite absoluto: seremos mesmo autores das nossas decisões, das nossas ações? Nesse sentido, o assunto é um tema acerca do poder. É uma questão ontológica (Será que existe? Em que termos?) e deontológica (Leva-nos a algum lado? Atribui-nos alguma competência? Legitima alguma penalização), entre um universo previsível e imprevisível. Pode abarcar, inclusivamente, de causalidade e de causação.

Todo o livro é um desafio: entre um diabo e um anjo que nos sussurram ao ouvido, esperamos que a voz do anjo seja a mais melodiosa e comovente. Depois escolhemos, não sabemos bem como, mas da escolha feita, seremos responsabilizados, eventualmente castigados. O crime pode bem ser mais do que motivo de ficção. E o castigo, mais do que uma prática social. Por isso, a obra mostra bem a falta que faz a reflexão, sobretudo para nos lembrar da nossa humilde e turva condição no meio de um mundo, para nós (como dizia Camões), tantas vezes desconcertado. Face à ligeireza do uso das palavras, há um mundo de ideias profundas associadas. E há, talvez, um impensado, que permanece.

Vamos encontrar ao longo desse volume ideias que estão estruturalmente associadas ao tema da responsabilidade: decisão, vontade, liberdade, agente ou agência, consciência, determinações biológicas (sobretudo em contexto neurológico), comportamento artificial, inteligência, legalidade e até responsabilidade social (coletiva) ou política. O tema é muitíssimo complexo e de uma atualidade evidente, e dá-nos conta do batalhão de gente a fazer trabalho de vanguarda.

A estrutura do livro apresenta-se em duas partes: I - Pensar a Responsabilidade; e II - Os Novos Contextos da Responsabilidade, precedidos por um prefácio luminoso e 
desconcertante de Manuel Curado, que coloca a "Responsabilidade sob o signo da Ciência, do Amor e da Sabedoria". Um prefácio que poderia ser um Posfácio, não perdesse, sob essa designação e lugar ordenado, a sua principialidade. Só esse prefácio justifica uma longa e pormenorizada reflexão e deve merecer ao leitor uma meditação atenta, demorada e crítica. O ponto de partida é um estado de ignorância. Curiosamente, o que fundamenta a ignorância acompanha inevitavelmente os percursos de investigação, ou seja, por mais que caminhemos, carregamos esse eterno desconhecido. Trata-se de uma prosa de filosofia, no seu melhor: sem partir de uma concepção consensual, a investida é demolidora e radical. $\mathrm{O}$ que põe em causa é tentar justificar, ou não, como o eu pode ser responsável, ou como os grupos podem ser responsabilizados. Como demonstra este texto, o historial da questão é não só vastíssimo como é, em si mesmo, construtivo do modo como se equaciona. No meio da discussão somos colocados à boleia de um comboio em andamento, que move consigo a problemática de sermos (seres humanos) meras marionetas (passivos) num mecanismo de que não fomos os relojoeiros, ou sermos sujeitos autónomos, capazes de decidir por nós próprios a lei dos nossos comportamentos. No percurso do argumento, percebemos que precisamos de investir numa linha científica ao mesmo tempo que ganhamos muito em retomar todo um universo literário de sabedoria, que é uma fonte praticamente inesgotável.

Ao tentar perceber como decidimos (se não o fizermos, que responsabilidade teremos?) enfrentamos um desafio inescapável. O mundo da legalidade é muitas vezes confrontado com os dados (às vezes tomados como evidências) das ciências médicas, como no caso de imputabilidade de responsabilidade a indivíduos que sofreram acidentes com consequências neurológicas), ou de dados das ciências cognitivas, como nos casos de ativações de zonas cerebrais, ou dos avanços em redes neuronais, ou de sistemas lineares ou não lineares, da cibernética, etc. Compreende-se a ansiedade do jurista, do economista, do político. Estes abanões têm consequências no seu trabalho edificante: edificar o quê? Com que tijolos, com que argamassa? E as dimensões históricas, sociais, culturais? As questões colocam-se a vários níveis: sou livre para decidir? Quem tem idade para o fazer? Que cidadania é necessária? Sou eu o responsável pelo que sou, ou sou o que de mim fizeram? Por mais avançados que estejamos em muitas áreas científicas e tecnológicas, a situação é tal qual a coloca Manuel Curado: a estrutura do problema não se alterou. Para avançar teríamos que compreender algo que ainda não o fizemos, teríamos que saber o que é a racionalidade humana e como funciona. E há outros níveis para se colocar este 
problema, para lá do epistemológico: a dimensão do amor e da sabedoria. Boas razões para acompanhar um texto através de narrativas tão antigas como os textos homéricos, ou os avanços das tecnologias e das ciências da mente mais recentes.

Quanto à primeira parte do livro, o contributo de Castro Caldas leva-nos a pensar $O$ contributo das neurociências para a compreensão do comportamento humano. O autor defende que esta noção da responsabilidade, tal como outras que foram sendo trabalhadas pela filosofia e pela psicologia, quando abordadas pelas neurociências, têm uma conotação muitas vezes diferente:

Os estudos experimentais nas neurociências - sobretudo os que concernem às técnicas de imagem cerebral - exigem uma operacionalização experimental muitas vezes complexa que implica a elaboração de um modelo processual. O valor do processo conduz muitas vezes a uma nova semântica distinta da original, pervertendo o sentido (4).

Para lá de tecnicidade semântica associada à pesquisa neurológica, o contributo de Castro Caldas insiste no conceito de cérebro social, como instância que funciona articulada com o cérebro individual. Importante também, é a informação relativa aos mecanismos funcionais cerebrais que foram revelados pelas pesquisas mais recentes da investigação clínica, mas não necessariamente em cérebros com patologias. Há contributos resultantes de estudos experimentais utilizando voluntários cujos cérebros não têm patologias, deixando pistas interessantes para entender os processos. Esses estudos revelam muitos dos meandros dos circuitos que atuam quando tomamos decisões, quando sentimos empatia, ou quando gerimos a nossa vida, quando comunicamos ou justificamos as nossas acções. Mas, como escreve: "É difícil de compreender completamente as bases biológicas do que se pode designar intencionalidade da ação que confere a responsabilidade ao seu ator." (4, p. 35).

O capítulo seguinte, de Manuel Curado, O Mito da Responsabilidade - contributos do pensamento olvidado, coloca o leitor perante um paradoxo: à semelhança da flexa de Zenão de Eleia, em que ela parece não se mover, movendo-se, com a responsabilidade, diz o filósofo, acontece algo semelhante. Se o universo for determinado e pudéssemos conhecer as leis que o governam, nada do que se fizesse teria acontecido decorrente de uma decisão pessoal. Tudo aconteceria porque tinha que acontecer. Se assim for, não nos cabe a nós qualquer responsabilidade. A não ser que, como advertiu Lucrécio, possa surgir um pequeno desvio, um detalhe imponderável, que pode ser a única base para uma responsabilidade 
perante o grande cenário da necessidade. O texto deste capítulo é cheio de elementos de um método de erudição, um trabalho notável onde sentimos claramente que o universo, físico e cultural, tem outros universos, e em que a visão única da história do mundo tem abafado muitos dados verdadeiramente inquietantes. Perante esta tessitura de histórias eruditas, a responsabilidade é questionada e lavada ao paradoxo.

Ana Elisabete Ferreira assina o texto seguinte, num estudo sobre a articulação $D a$ Neuroética ao Neurodireito - vanguardas da responsabilidade. De um conjunto muito vasto de problemas colocados pela neuroética, a autora foca-se em quatro questões fundamentais: a primeira é sobre a eventual (e defendida) moralidade inata, um dado que as neurociências (de determinada orientação, diríamos nós) supõe, como que uma inclinação biológica para partilharmos certos princípios, que são comuns a diversas manifestações da vontade de cooperação dos indivíduos. A segunda centra-se na dimensão emocional da responsabilidade, que decorre também das teses das neurociências (Ana Elisabete Ferreira evoca sobretudo os estudos de A. Damásio). Aqui conta a vontade de pertencer a um grupo. Isto é importante, pois pode constituir uma base para a fundação do direito assente num "gene da responsabilidade jurídica" (6, p. 92). Os sentimentos de culpa e de vergonha constituem operadores de responsabilidade determinantes, e que são do foro emocional. A terceira questiona a relação da (neuro)ética com o (neuro)direito, em que a grande questão é a de saber até que ponto o conhecimento das neurociências deve condicionar os sistemas jurídicos. A conclusão defendida pela autora é a de que "do mesmo modo que a moralidade inata pode distinguir-se dos padrões morais de conduta, embora estes dependam dos primeiros, também o sentimento jurídico inato se distingue das construções jurídicas" (6, p. 97). A última questão diz respeito à relação que deve se estabelecer entre os postulados normativos e os postulados científicos. Nessa parte, argumenta-se que há uma abordagem muito específica, mas há sempre um ambiente antropológico geral que constitui o horizonte da abordagem jurídica. Por último, e em jeito de conclusão, dir-se-ia que o direito tem que considerar os dados científicos, mas deve também não esquecer o seu envolvimento num mundo em construção, com esperança.

Segue-se um texto de Luís Moniz Pereira e Fernando da Costa Cardoso, intitulado $A$ Ilusão do que conta como Agente. Aqui se aborda a questão da autonomia, sob o prisma da cibernética/inteligência artificial. Os dados colocados pelas palavras dos autores vão na formulação do objectivo do texto: 
[...] fornecer uma simples categorização de diferentes tipos de sistemas que podem ser descritos como máquinas morais (ou agentes éticos artificiais), de modo que, se se permitir que as ferramentas críticas desenvolvidas sejam reincorporáveis, o filósofo terá como objectivo, em primeiro lugar, destacar outras conexões $(7$, p. 103).

Este é um terreno de estudo muito interessante no tratamento das questões éticas, pois envolve-se com as possibilidades da constituição de máquinas morais, ou sistemas artificiais que possam decidir eticamente. $O$ artigo revela a necessidade de repensar a autonomia, o papel das aparências e da identidade e os fatores que determinam aquilo que valorizamos.

A terminar a Parte I, aparece o texto de João Vaz Rodrigues, As Esferas da Responsabilidade: uma revisão dos princípios bioéticos. Trata-se de um capítulo alicerçado numa visão de um jurista a braços com questões abordadas por muitos filósofos: saúde, dignidade, respeito, solidariedade, vulnerabilidade e cuidado. A sua perspetiva resulta de um trabalho reflexivo sobre estes valores, com a preocupação de incluir na fundamentação de um direito ligado à bioética todo um conjunto de tópicos que se colocam a uma ética da relação. É um texto de um humanista, de revisitação dos temas clássicos da ética e da sua aplicação ao direito bioético. No fundo, o autor lança um repto inquestionável: as decisões legais estão impregnadas de um fundo filosófico indelével. E não há como dar a volta, se o objetivo é, como este, o de procurar estabelecer pontes, passagens conceptuais, entre a grande tradição do direito e aquilo sobre o que se legisla.

A Parte II - Os Novos Contextos da Responsabilidade -, abre com um texto sobre o programa de melhoramento humano e uma sua aplicação na problemática bioética do desporto: Human Enhancement en el ámbito deportivo? Algunas notas sobre sus implicaciones jurídicas y consideraciones éticas, de Elena Atienza Macías. O que está em causa, nesse discurso, é o tema do melhoramento artificial tanto a nível emocional e cognitivo como físico. Desde a estratégia da dopagem psicofármaca até à dopagem genética, o problema é o de se discutir se há ou não legitimidade para a sua utilização na competição desportiva.

O capítulo seguinte, da autoria de Adalberto Fernandes, intitula-se Neuroimagem da decisão de fim-de-vida e coloca-nos perante uma técnica que traz problemas bioéticos novos: pode alguém em estado vegetativo pronunciar-se sobre a sua eventual vontade sobre o fim da sua vida? A problemática, em termos de direito, é inquietante: se é possível ter, através da tecnologia de neuroimagem, a certeza de que o sujeito se pode manifestar sobre 
a sua situação, pode essa sua comunicação ser aceite como matéria legal? Em primeiro lugar, é preciso definir-se o próprio conceito de estado vegetativo. Depois, é necessário saber se a comunicação feita através de uma neuroimagem é suficientemente clara e totalmente legítima para ser aceite. Há argumentos pró e contra. O texto termina com uma tomada de posição:

A neuroimagem, como qualquer contributo do campo da ciência, não termina com o ato interpretativo reservado ao Direito, porque é ainda perante uma não-transparência, i.e., a alteridade, em que tanto o Direito como a neuroimagem se deslocam" (9, p. 169).

Steven S. Gouveia escreve o texto seguinte, O Problema da lacuna da responsabilidade na inteligência artificial, defendendo que é possível encontrar uma solução para a lacuna da responsabilidade ou responsibility gap. Essa temática tem vindo a imporse à medida que os avanços da robótica, da inteligência artificial e do progressivo desempenho produtivo baseados em trabalho de máquinas se vai tornando mais comum. No campo do direito constitui uma área extremamente desafiante, pois coloca a questão da responsabilização que se pode atribuir a um sistema artificial, dado que não é normal atribuirse responsabilidade senão a indivíduos dotados de intencionalidade. O cenário agrava-se quando assistimos à criação de sistemas artificiais autónomos capazes de evoluir por si mesmos, com a programação adequada para se adaptarem a novos contextos através do seu sistema de aprendizagem, que é o itinerário que tem vindo a ser desenhado pela Inteligência Artificial. Naturalmente que problemas de ordem ética e legal se colocam. Até onde estender o perímetro da legalidade? Haverá distinção entre o nível de responsabilidade para um operador humano e um operador mecânico? O autor avança com uma tese: "Defenderemos que uma possível solução para esta lacuna será a aplicação inovadora da ideia de Moralidade Distribuída (distributed morality), avançada por Luciano Floridi, ao conceito de Responsabilidade" (10, p. 176).

Robson Antão de Medeiros, em Biotecnologia, deficiência e responsabilidade civil do estado frente aos novos direitos, situa o ponto central da problemática naquilo que concerne à necessidade de se precisar o conceito de deficiência, de pessoa com deficiência, dos seus direitos. O desenvolvimento de NBIC (Nanotecnologias, Biotecnologias, Tecnologias da Informação, Ciências Cognitivas) traz consigo um conjunto de problemas legais de enorme dificuldade, pois estas inovações tecnológicas acrescentam outras dimensões às realidades naturais com que o edifício legislativo foi construído. Como diz o autor: 
[...] há toda uma discussão não somente científica, mas bioética e jurídica, em que em meio a essa simbiose "corpo e tecnologia" o ser humano vai incorporando realmente em seu corpo essas tecnologias, resultando em novas configurações - o híbrido. São corpos virtualizados via informática, corpos reconstruídos por meio de próteses biônicas de última geração, corpos modificados geneticamente, em suma, corpos híbridos [...] (11, p. 197).

Miguel Pais-Vieira e Carla Pais-Vieira deixam-nos um capítulo interessantíssimo, Interfaces cérebro-máquina e os limites da responsabilidade, apresentando o seu programa:

\begin{abstract}
É intenção dos autores apresentar um texto simples que permita a académicos e não-académicos uma compreensão de quais as variáveis que, estando envolvidas nas interfaces cérebro-máquina, podem condicionar o sentido de agência, a tomada de decisão e, consequentemente, a responsabilidade que o indivíduo apresenta sobre as suas ações. Veremos que a manipulação dos circuitos cerebrais pode levar à realização de determinadas ações sem que o indivíduo tenha a plena noção do móbil dos seus atos." (12, p. 203).
\end{abstract}

Os interfaces cérebro-máquina têm potencialidades que seriam inimagináveis há umas décadas. A capacidade de fazer com que o agente possa desencadear ações de que ele próprio não tem plena consciência significa que uma pessoa pode ser levada a tomar uma decisão, alterando algo que foi quase sempre pensado como uma condição do ser humano, sobretudo nas suas ações racionais, que é a auto-percepção. Isso pode por em causa quase tudo aquilo que se defendeu ser atributo do ser responsável: consciência e vontade.

Por último, surge um texto de Ana Isabel Cardoso Figueiredo Sol, com o título Vanguardas da responsabilidade na era biotecnológica: da perspectiva habermasiana aos desafios biopolíticos. Neste texto a autora explora, a partir da teoria de J. Habermas, sobretudo através da sua obra O Futuro da Natureza Humana: a consciencialização dos perigos do progresso tecnológicos desvinculados do espírito crítico. A preocupação decorrente da leitura da obra de Habermas, na qual este sociólogo alerta precisamente para o perigo da espécie humana perder alguma da sua capacidade de autocompreensão normativa. Não se trata de uma fobia ao desenvolvimento tecnológico em si mesmo, mas de limitações que se anunciam. Com a aproximação a um futuro pós-humano, trata-se de salvaguardar alguns mecanismos que mantenham a capacidade de nos pensarmos a nós mesmos enquanto indivíduos e enquanto espécie. 
Trata-se, pois, de um livro que levanta questões acerca da responsabilidade, de um ponto de vista não meramente técnico ou civilizadamente correto. No seu todo vemos como esta noção se cruza com todo um universo conceptual e disciplinar e como os desenvolvimentos científicos e técnicos estão carregados de dilemas ético-jurídicos. E como faz falta reflectir sobre um assunto tremendo.

\section{Referências}

1. Curado M, Pereira AD, Ferreira AE (orgs.). Vanguardas da Responsabilidade: Direito, Neurociências e Inteligência Artificial. (Col. Centro de Direito Biomédico, 27). Coimbra: Petrony, 2019. [ISBN 978-972-685-278-0]

2. Pereira AD. Nótula Introdutória. In: Curado $M$, Pereira AD, Ferreira AE (orgs.).

Vanguardas da Responsabilidade: Direito, Neurociências e Inteligência Artificial. (Col. Centro de Direito Biomédico, 27). Coimbra: Petrony, 2019. [ISBN 978-972-685-278-0]

3. Curado M. A Responsabilidade sob o Signo da Ciência, do Amor e da Sabedoria (Prefácio). In: Curado M, Pereira AD, Ferreira AE (orgs.). Vanguardas da Responsabilidade: Direito, Neurociências e Inteligência Artificial. (Col. Centro de Direito Biomédico, 27). Coimbra: Petrony, 2019. [ISBN 978-972-685-278-0]

4. Caldas AC. Contributo das Neurociências para a Compreensão do Comportamento Responsável. In: Curado M, Pereira AD, Ferreira AE (orgs.). Vanguardas da Responsabilidade: Direito, Neurociências e Inteligência Artificial. (Col. Centro de Direito Biomédico, 27). Coimbra: Petrony, 2019. [ISBN 978-972-685-278-0]

5. Curado M. O Mito da Responsabilidade: Contributos do Pensamento Olvidado. In: Curado M, Pereira AD, Ferreira AE (orgs.). Vanguardas da Responsabilidade: Direito, Neurociências e Inteligência Artificial. (Col. Centro de Direito Biomédico, 27). Coimbra: Petrony, 2019. [ISBN 978-972-685-278-0]

6. Ferreira AE. Da Neuroética ao Neurodireito: Vanguardas da Responsabilidade. In: Curado M, Pereira AD, Ferreira AE (orgs.). Vanguardas da Responsabilidade: Direito, Neurociências e Inteligência Artificial. (Col. Centro de Direito Biomédico, 27). Coimbra: Petrony, 2019. [ISBN 978-972-685-278-0]

7. Pereira LM, Cardoso FC. A llusão do que conta como Agente. In: Curado M, Pereira AD, Ferreira AE (orgs.). Vanguardas da Responsabilidade: Direito, Neurociências e Inteligência Artificial. (Col. Centro de Direito Biomédico, 27). Coimbra: Petrony, 2019. [ISBN 978-972685-278-0]

7. João Vaz Rodrigues. As Esferas da Responsabilidade: Uma Revisão dos Princípios Bioéticos. In: Curado M, Pereira AD, Ferreira AE (orgs.). Vanguardas da Responsabilidade: Direito, Neurociências e Inteligência Artificial. (Col. Centro de Direito Biomédico, 27).

Coimbra: Petrony, 2019. [ISBN 978-972-685-278-0] 
8. Macías EA. ¿Human Enhancementen el Ámbito Deportivo? Algunas Notas sobre sus Implicaciones Jurídicas y Consideraciones Éticas. In: Curado M, Pereira AD, Ferreira AE (orgs.). Vanguardas da Responsabilidade: Direito, Neurociências e Inteligência Artificial. (Col. Centro de Direito Biomédico, 27). Coimbra: Petrony, 2019. [ISBN 978-972-685-278-0]

9. Fernandes A. Neuroimagem da Decisão de Fim-de-vida. In: Curado M, Pereira AD, Ferreira AE (orgs.). Vanguardas da Responsabilidade: Direito, Neurociências e Inteligência Artificial. (Col. Centro de Direito Biomédico, 27). Coimbra: Petrony, 2019. [ISBN 978-972685-278-0]

10. Steven S. Gouveia. O Problema da Lacuna da Responsabilidade na Inteligência Artificial. In: Curado M, Pereira AD, Ferreira AE (orgs.). Vanguardas da Responsabilidade: Direito, Neurociências e Inteligência Artificial. (Col. Centro de Direito Biomédico, 27). Coimbra: Petrony, 2019. [ISBN 978-972-685-278-0]

11. Medeiros RA. Biotecnologia, Deficiência e Responsabilidade Civil do Estado frente aos Novos Direitos. In: Curado M, Pereira AD, Ferreira AE (orgs.). Vanguardas da Responsabilidade: Direito, Neurociências e Inteligência Artificial. (Col. Centro de Direito Biomédico, 27). Coimbra: Petrony, 2019. [ISBN 978-972-685-278-0]

12. Pais-Vieira M, Pais-Vieira C. Interfaces Cérebro-Máquina e os Limites da Responsabilidade. In: Curado M, Pereira AD, Ferreira AE (orgs.). Vanguardas da Responsabilidade: Direito, Neurociências e Inteligência Artificial. (Col. Centro de Direito Biomédico, 27). Coimbra: Petrony, 2019. [ISBN 978-972-685-278-0]

13. Sol AICF. Vanguardas da Responsabilidade na Era Biotecnológica: Da Perspectiva Habermasiana aos Desafios Biopolíticos. In: Curado M, Pereira AD, Ferreira AE (orgs.). Vanguardas da Responsabilidade: Direito, Neurociências e Inteligência Artificial. (Col. Centro de Direito Biomédico, 27). Coimbra: Petrony, 2019. [ISBN 978-972-685-278-0] 